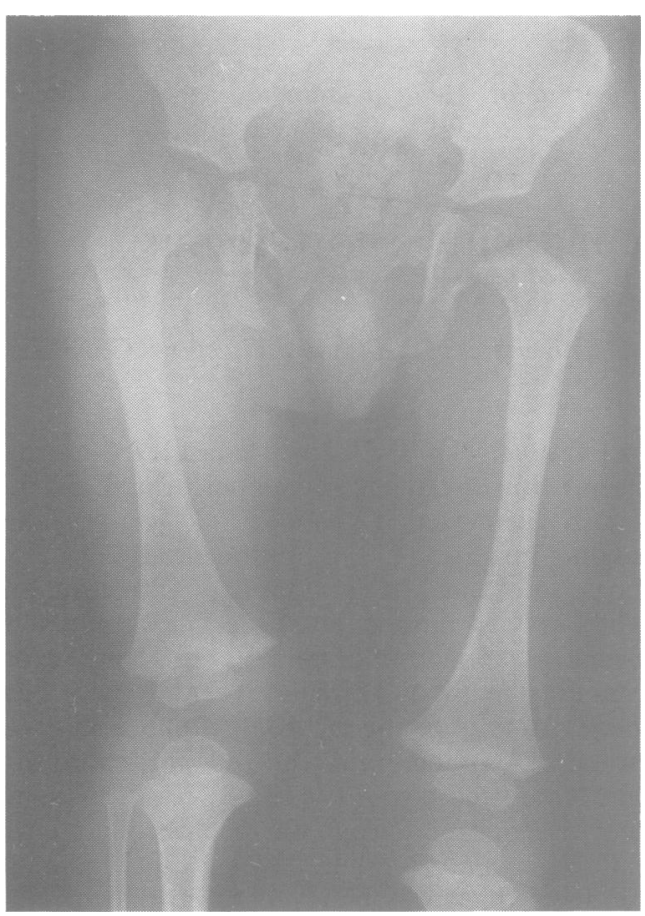

FIG 2 Twin 2 aged 17 months.

circumference of $58.5 \mathrm{~cm}$ and the absence of neurological findings. ${ }^{5}$

\section{Discussion}

With the present report there are now four instances of familial recurrence of congenital short femur. Ring $^{2}$ described a pair of concordant twins with congenital short femur in 1959 , but no comment was made about their zygosity. Kelly ${ }^{3}$ noted that a third degree relative had a curved femur, and in his comprehensive family study $\mathrm{Hamanishi}^{4}$ found only one familial recurrence in first cousins among $56 \bar{s}$ families studied. In this study, ${ }^{4}$ no raised parentato ages were found and only one set of parents waso consanguineous. Furthermore, three sets of discor- $\overline{-\bar{s}}$ dant twins of uncertain zygosity have been $\mathbb{\Omega}$ reported. ${ }^{46}$

With the exception of thalidomide, which is usually associated with more severe femoral defects, $\vec{\circ}$ no consistent environmental factors have been $\overrightarrow{\vec{H}}$ identified. Unifactorial inheritance is most unlikely and the observed patterns of familial recurrence and ${ }_{3}$ twin concordance favour multifactorial inheritanceco for simple femoral hypoplasia.

We wish to thank the Wellcome Trust and the National Fund for Research into Crippling Diseases ${ }^{\AA}$ for financial support.

\section{References}

' Rogala EJ, Wynne-Davies R. Littlejohn A, Gormley J. Congenital limb anomalies: frequency and actiological factors. Data from the Edinburgh Register of the newborn (1964-1968).

J Med Genet 1974:11:221-33.

2 Ring PA. Congenital short femur. Simple femoral hypoplasia. $J^{\prime}$ Bone Joint Surg (Br) 1959:41:73-9.

${ }^{3}$ Kelly TE. Proximal focal femoral deficiency (familial). Birth Defects 1974:10(12):508-9.

+ Hamanishi C. Congenital short femur. Clinical, genetic and epidemiological comparison of the naturally occurring condition with that caused by thalidomide. J Bone Joint Surg $(B r) \unrhd$ 1980;62:307-20.

5 Asch AJ. Myers GJ. Benign familial macrocephaly. Report of a음 family and review of the literature. Pediatrics 1976;57:535-40.

6 Westin GW, Gunderson FO. Proximal femoral focal deficiency: a review of treatment experiences. In: Aitken GT, ed. Proximal femoral focal deficiency. A congenital anomaly. Symposium held in Washington, June 13,1968. Washington: National Academy of Sciences, 1969:1-22.

Correspondence and requests for reprints to Dr J Me. Connor, Duncan Guthrie Institute of Medical Gene-尺्र tics, Yorkhill, Glasgow G3 8SJ.

\title{
Poland syndrome associated with 'morning glory' syndrome (coloboma of the optic disc)
}

\author{
D T PIŠTELJIĆ*, D VRANJEŠEVIC**,S APOSTOLSKI†, AND \\ D D PIŚTELJIC**
}

${ }^{*}$ Institute for Neurology and Psychiatry of Childhood and Adolescence, and +Clinic for Neurology, 11000 Belgrade, Yugoslavia.

SUMmary A 12 year old girl with the Poland syndrome and the 'morning glory' syndrome is described. The patient presented with absence

Received for publication 2 March 1985.

Revised version accepted for publication 4 July 1985. of the left pectoralis major muscle, hypoplasia ${ }^{\infty}$ of the left arm, symbrachydactyly, and ipsi- $\frac{0}{0}$ lateral coloboma of the optic disc. This is the요 first report of the association of these two क्षे congenital anomalies. 


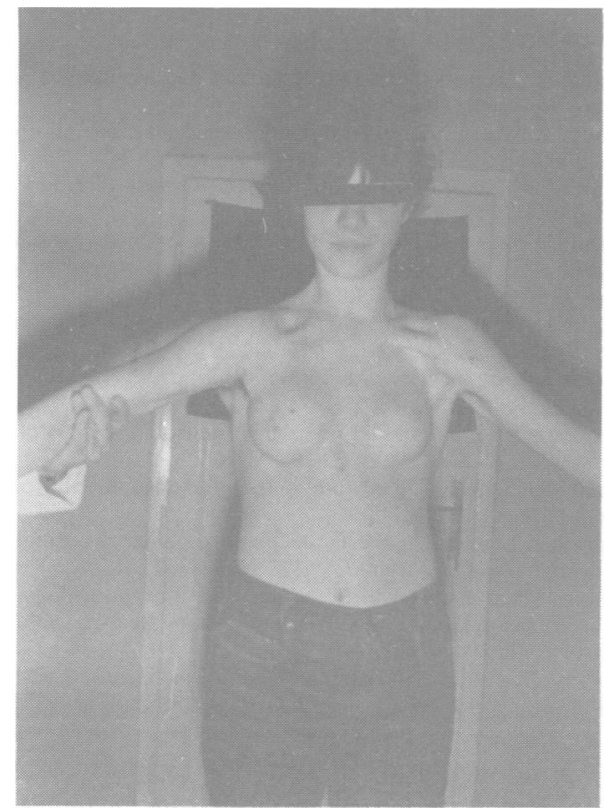

FIG 1 Absence of the sternal portion of the left pectoralis major muscle with ipsilateral breast and nipple hypoplasia.

Poland syndrome consists of absence of the sternal portion of the pectoralis major muscle and symbrachydactyly. ' 'Morning glory' syndrome ${ }^{2}$ or coloboma of the optic disc is thought to result from disturbances in closure of the embryonal optic fissure. Congenital malformations of the optic disc are seldom specifically distinguishable without histological examination, but they are usually represented by specific clinical findings. We report a patient with a combination of these abnormalities involving the same side.

\section{Case report}

The patient was a 12 year old girl with signs of Poland syndrome on the left side and coloboma of the left optic disc. The family history was negative for both anomalies.

Aplasia of the sternal portion of the left pectoralis major muscle was associated with hypoplasia of the breast and nipple and reduced axillary hair (fig 1). The left arm was thinner and $2.5 \mathrm{~cm}$ shorter than the right. The middle phalanges of the fingers of the left hand were missing (symbrachydactyly) (fig 2).

The right eye was myopic with a visual acuity of $6 / 6-10 \cdot 0$. The left eye was blind, divergent, and raised. The visual field and colour perception were normal in the right eye and intraocular pressures

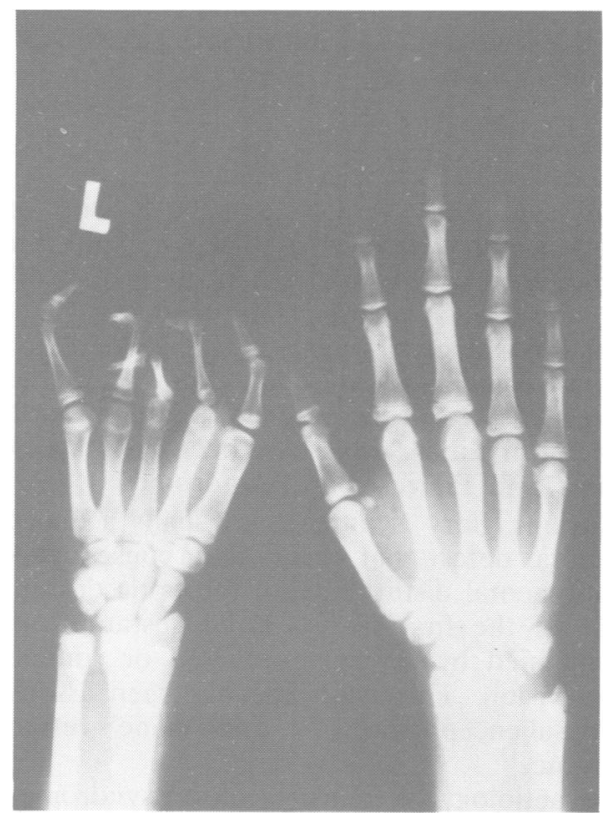

FIG 2 Symbrachydactyly of the left hand.

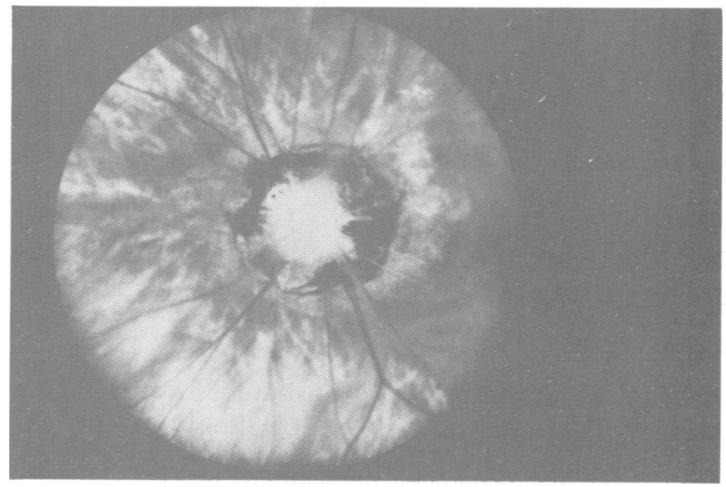

FIG 3 Coloboma of the optic disc.

were normal. The appearance of the right fundus was normal but the left fundus showed features of the 'morning glory' syndrome (fig 3). Fluorescein angiography indicated normal duration of retinal blood vessel filling on both sides. ERG was normal on the right but subnormal for the left eye.

Neurological, neuroradiological, neuroendocrinological, and EEG examinations revealed no abnormalities. Antibody titre measurement showed no antibody production against $\mathrm{CMV}$, rubella, $\mathrm{HSV}_{1}$, 
and $\mathrm{HSV}_{2}$ viruses. The karyotype was $46, \mathrm{XX}$ (in five cells).

\section{Discussion}

Poland syndrome is often associated with other congenital abnormalities: hypoplasia of the breast and nipple, reduced axillary hair, anomalies of the bony thorax, syndactyly, cleft hand deformities, ${ }^{3}$ preaxial polydactyly type 1 , absence of extensor tendons of the hand and hypoplastic thenar muscles, ${ }^{4}$ dextrocardia ${ }^{5}$ skeletal and genitourinary tract abnormalities. ${ }^{6}$ It has also been associated with Möbius ${ }^{7}$ and Pierre-Robin ${ }^{8}$ syndromes.

'Morning glory' syndrome is usually a unilateral congenital defect that occurs as a consequence of developmental disturbance of the optic disc in the course of the first six weeks of gestation and is accompanied by severely impaired or completely absent vision. This syndrome has been associated with basal encephalocele ${ }^{9}{ }^{10}$ and Duane's retraction syndrome. ${ }^{11}$

The aetiology of 'morning glory' syndrome and the nature of its association with Poland syndrome remain unclear.
References

' Poland A. Deficiency of the pectoralis major muscles. Guy's Hosp Rep 1841;6:191-5.

2 Kindler F. Morning glory syndrome: unusual congenital optic disk anomaly. Am J Ophthalmol 1970;69:376-83.

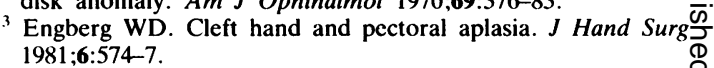

${ }^{4}$ Senrui H, Egawa T, Horiki A. Anatomical findings in the hands of patients with Poland's syndrome. Report of four cases. Jo Bone Joint Surg (Am) 1982;64:1079-82.

5 Hanka S. Dextrocardia associated with Poland's syndrome. Pediatr 1975;86:312.

6 Oppolzer A, Sacher M. Poland syndrom. Klin Paedr $\vec{\omega}$ 1983;195:135-7.

7 Sugarman GI, Stark HH. Möbius syndrome with Poland's anomaly. J Med Genet 1973;10:192-6.

$\checkmark$ Wood VE, Sandin C. The hand in the Pierre Robin syndrome. $J$ Hand Surg 1983;8:273-6.

9 Caprioli J, Lesser RL. Basal encephalocoele and morning glory syndrome. Br J Ophthalmol 1983;67:349-51.

10 Koenig SB, Naidich TP, Lissner G. The morning gloryo syndrome associated with sphenoidal encephalocoele. Ophthal-J mology 1982;89:1368-73.

1 Kawano K, Fujita S. Duane's retraction syndrome associated

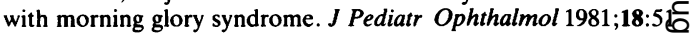
-4 .

Correspondence and requests for reprints to $\mathrm{Dr} \mathrm{D}_{-}^{-}$ Pišteljić, Institute for Neurology and Psychiatry of Childhood and Adolescence, Dr Subotića 6a, 110009 Belgrade, Yugoslavia.

\section{Interstitial deletion of chromosome $4 \mathrm{q}$ diagnosed prenatally}

\section{J M CAMPBELL*, J WILLIAMS $\dagger$, AND G BATCUP}

Departments of Obstetrics and Gynaecology* and Pathology $\neq$, University of Leeds; and †Department of Cytogenetics, St James's University Hospital, Leeds.

SUMmARY The prenatal diagnosis of $4 \mathrm{q}$ deletion was made as a result of amniocentesis for high serum alphafetoprotein

\section{Case report}

A 27 year old primigravida (husband 28 years old), a non-smoker with no history of illness, $x$-ray ex-

TABLE Characteristics of $4 q$ deletion syndrome.

\begin{tabular}{lc}
\hline & Previous cases \\
\hline $\begin{array}{l}\text { Mental retardation } \\
\text { Craniofacial anomalies }\end{array}$ & $10(100 \%)^{*}$ \\
$\quad$ Mid-facial asymmetry or hypoplasia & $13(92.8 \%)$ \\
Cleft lip & $5(35.7 \%)$ \\
Cleft palate & $13(92.8 \%)$ \\
Micrognathia & $12(85.7 \%)$ \\
Abnormal auricles & $14(100 \%)$ \\
Abnormalities of fingers and/or toes & $13(92.8 \%)$ \\
Cardiac anomalies & $11(78.6 \%)$ \\
\hline
\end{tabular}

*Cases of Townes $e t$ at (died at birth), Mitchell et at (one died at 1 hour, one died at 23 days), and Chudley et al ${ }^{11}$ (reported at age of 1 day with no further information given) are not included.

Received for publication 12 April 1985

Revised version accepted for publication 16 September 1985. posure, or medication in early pregnancy, was seen after 13 weeks' amenorrhoea. In the 15 th week of gestation the serum alphafetoprotein was found too be high on two occasions and therefore amnio- -0 centesis was performed in the 17 th week. The amniotic fluid AFP level was normal. However, theo fetal karyotype showed a deletion of the long arm of $₹$ chromosome 4 . The parents chose to terminate the응 pregnancy.

The fetus (weighing $360 \mathrm{~g}$ ) had a complete bilateral cleft lip and palate and there were deformities of the fourth finger on the right hand and the second toe on the left foot (fig $1 \mathrm{a}$ and $b$ ). Necropsy showed a preductal coarctation of the aorta and a double superior vena cava.

CYTOGENETIC STUDIES

$\mathrm{G}$ banding showed an interstitial deletion in all cells@ analysed. The karyotype was interpreted as:0 46,XY,del(4)(pter $\rightarrow$ q21::q27 $\rightarrow$ qter) (fig 2). Thisō finding was confirmed in fetal skin and lung tissue $\vec{\Phi}$ obtained after termination. The karyotypes of bothत्ष parents were normal. 